\title{
Um novo olhar sobre a linguagem jurídica
}

Janine Aguiar Jacob Vaz

Acadêmica do curso de Direito do Centro Universitário de Volta Redonda ( UniFOA)

\section{Michele Sales de Carvalho}

Acadêmica do curso de Direito do Centro Universitário de Volta Redonda ( UniFOA)

\section{Rebeca Baltazar Chaves}

Mestre em Ensino em Ciências da Saúde e do Meio Ambiente ( UniFOA). Especialista em Gestão Estratégica em Marketing Digita ( UCAM)1. Jornalista (UniFOA). Graduanda em Direito ( UniFOA) Professora do curso de Jornalismo e Publicidade e Propaganda (UniFOA).

\section{Maricineia Pereira Meireles da Silva}

Mestrado Acadêmico Interdisciplinar em Educação e Saúde ( UniFOA). Mestrado em Gestão e Estratégia em Negócios ( UFRRJ). Especialização em Língua Portuguesa. Professora do curso de Direito (UniFOA). 


\section{Resumo}

Este $\mathrm{O}$ presente trabalho visa à contribuição com o processo de eliminação do preconceito linguístico, com foco na linguagem jurídica extremamente formal, o "juridiquês" (neologismo que designa o uso desnecessário e excessivo do jargão jurídico e de termos técnicos do direito). Em primeiro plano, traça-se uma contextualização e análise do discurso jurídico extremamente formal, com intuito de refletir sobre a real necessidade do uso desse tipo de linguagem, tendo em vista o modelo de informação Shannon-Weaver como ideal de comunicação. Parte-se da premissa de que a realidade social do Brasil não condiz com este tipo de aplicabilidade, e diante disso alguns operadores do direito têm alterado a forma de redigir sentenças e outras peças processuais. A fundamentação teórica desta pesquisa é embasada em Bagno (2007) e Bourdieu (1989).

Palavras-chave: Discurso Jurídico. Comunicação. Preconceito linguístico

\section{Abstract}

The present paper aims to contribute to the process of eliminating linguistic prejudice, focusing on the extremely formal legal language, the "juridique" (neologism which refers to the unnecessary and excessive use of legal jargon and technical terms of law). In the foreground, a contextualisation and analysis of the extremely formal juridical discourse is traced in order to reflect on the real need to use this type of language, considering the Shannon-Weaver information model as an ideal of communication. It is based on the premise that the social reality of Brazil does not fit with this type of applicability, and before this some legal operators have changed the way of writing sentences and other procedural pieces. The theoretical basis of this research is based on Bagno (2007) and Bourdieu (1989).

Keywords: Legal Discourse. Communication. Linguistic prejudice. 


\section{Introdução}

Comunicar-se é fazer uma troca de informações. Fazer-se entender de forma clara e precisa, cuja mensagem transmitida tenha coesão e coerência. Para haver uma comunicação eficaz e eficiente é preciso que haja interação dos participantes, e de todos os elementos que formam a comunicação humana.

O propósito da linguagem jurídica é construir uma comunicação eficaz e eficiente com a sociedade. Uma comunicação é eficaz quando ela é feita de forma correta, bem redigida, com clareza, precisão e ordem lógica, e a eficiência desse processo comunicativo acontece quando ele é compreendido e assimilado por todos os receptores.

A Constituição Federal de 1988 preconiza como direito fundamental do cidadão brasileiro o acesso à justiça. Além desta natureza jurídica, a $1^{\text {a }}$ Convenção Interamericana sobre Direitos Humanos de São José da Costa Rica, da qual o Brasil é signatário, eleva o acesso à justiça a uma prerrogativa de Direitos Humanos. Esse breve cenário é capaz de constatar a tamanha relevância acerca da temática.

Entretanto, esse acesso é mediado pelos operadores do direito e por todos os trâmites formais necessários para a realização de ações judiciais. Ademais, parte da população não possui sequer conhecimento básico sobre seus direitos e isso pode ser previsto mediante a análise de pesquisas recentes sobre a educação no Brasil. Dados de 2015 do Instituto Brasileiro de Geografia e Estatística (IBGE) constatam que 8,0\% da população brasileira acima dos 15 anos é analfabeta. Pesquisa realizada pela Organização para a Cooperação e Desenvolvimento Econômico (OCDE) divulgada em 2018 mostra que $52 \%$ das pessoas com idade entre 25 e 64 anos não concluíram o Ensino Médio e apenas $17 \%$ possui diploma de ensino superior1.

Diante desse panorama, este trabalho busca considerar como um linguajar mais simples e condizente com a realidade educacional do nosso país pode colaborar com o acesso à justiça e fazer com que o cidadão se sinta inserido na sociedade e na prerrogativa de seus direitos. O trabalho justifica-se por tratar do Direito não só de

$1 \mathrm{G1}$ : Mais da metade dos brasileiros não tem diploma do ensino médio, aponta OCDE. Disponível em <https://g1.globo.com/educacao/noticia/2018/09/11/mais-da-metade-dos-brasileiros-nao-tem-diplomado-ensino-medio-aponta-ocde.ghtml> Acesso em 08 jun. 2019. 
modo positivista e aplicável, mas sim com um teor humanizado e funcional. Afinal, tem-se como premissa que a 'comunicação não é o que você diz, mas o que o outro entende'. Ora, será que a nossa população possui, de fato, capacidade de entender as normas e palavras cultas e em latim empregadas rotineiramente no ambiente jurídico?

Cabe destacar que não se trata aqui de uma crítica rígida ao direito tradicional, mas sim uma reflexão sobre a operabilidade e democratização do negócio jurídico. A metodologia empregada é de ordem qualitativa, baseada em revisão bibliográfica e pesquisa sobre casos concretos nos quais os juízes ou ordenadores utilizaram uma linguagem acessível e compreensível para com os relacionados nos processos. $\mathrm{O}$ principal autor selecionado para tratar do preconceito linguístico foi o linguista Marcos Bagno que se destaca por sua crítica nesse sentido - sabendo-se também a necessidade de relativizar seu teor mediante a necessidade de uma ordem séria para a prática jurídica.

\section{Fundamentação Teórica}

\section{A LINGUAGEM JURÍDICA}

A prática jurídica é consensualmente repleta de um tipo de formalismo que pode ser observado em diversos ambientes que permeiam o Direito e os que ele representa. Desse modo, pode-se observar essa prática, por exemplo: na linguagem técnica, nos trajes, na burocracia que envolve os processos e até mesmo na forma de acesso a justiça. (ANDRADE, 2015)

A linguagem jurídica é tão formal e própria que até criou-se uma expressão o "juridiquês", que quando posto em prática torna a linguagem jurídica um "idioma" desconhecido e inacessível para a maioria das pessoas. $\mathrm{O}$ uso de termos técnicos como em outras áreas sempre serão necessários, pois são comuns dentro do âmbito do direito, porém, o que se deve evitar é o preciosismo no âmbito jurídico, que se caracteriza por um uso excessivo de expressões em latim e expressões arcaicas que já caíram em desuso. Essa prática ainda é constantemente aplicada no meio jurídico, pois parte dos profissionais acreditam que escrever bem é escrever difícil. (Idem)

Para melhor compreensão desse preciosismo, pode-se citar como exemplo as diversas maneiras de escrever 'petição inicial', que no juridiquês torna-se 'peça de 
intróito', 'peça exordial', 'peça incoativa', 'peça ovo' ou 'peça prodômica'. Ou ainda, 'alvazir de piso' no lugar de 'juiz de primeira instância'; 'caderno indiciário' ao invés de 'inquérito policial' e 'consorte virago' para se referir à 'esposa'. (Ibidem)

Muitas vezes são usadas expressões e abreviaturas que sequer os magistrados compreendem. Ora, se existem expressões de difícil acesso até para quem atua na área, o que se dirá de uma pessoa leiga.

\section{A COMUNICAÇÃO}

Não se pode esquecer que a linguagem é o meio através do qual o homem se comunica, e esta é uma prática social básica. Sabe-se também que um dos fatores a serem observados durante a comunicação é o grau de conhecimento do destinatário, uma vez que precisamos saber se o mesmo terá conhecimento adequado para perfeita decodificação da mensagem, tendo assim, completo entendimento das informações que lhes foram passadas. Afinal, como diz o dito popular: comunicação não é o que você diz, mas o que o outro entende.

Escrever bem implica necessariamente a obtenção de uma resposta correta; resposta correta é aquela que corresponde à ideia que temos em mente e desejamos passar ao leitor. Este primeiro segredo já aponta para uma das funções essenciais da comunicação escrita, a saber: provocar uma reação ou resposta. (BLIKSTEIN, 2002, p. 15)

Diante desse contexto, pode-se considerar a necessidade de adequar a acessibilidade linguística nos processos jurídicos mediante o modelo estabelecido por Shannon-Weaver na década de 1940, mas que ainda é referência nos estudos comunicacionais. Segundo os autores, o processo de comunicação é percebido como: uma mensagem é codificada e enviada de um transmissor para um receptor por meio de um canal. Entretanto, nesse caminho, alguns ruídos podem ocorrer e prejudicarem a interpretação do receptor, que se não decodificar corretamente a mensagem, não é capaz de enviar um feedback e por isso, a comunicação não ocorre de fato. Afinal, a comunicação é um processo dialógico. 
Blikstein corrobora nesse sentido ao afirmar que "comunicação é tornar comum o nosso pensamento ao outro". Os termos "comunicar" e "comunicação" provêm justamente da palavra comum.

Eis, pois, o segundo segredo da comunicação escrita: escrever bem é tornar o nosso pensamento conhecido dos outros, ou, melhor ainda, escrever bem é tornar comum aos outros o nosso pensamento. Esta necessidade de tornar comum responde a outra função básica da comunicação e, para que se tenha uma ideia de como é essencial esta função, basta lembrar que os termos comunicar e comunicação provêm justamente da palavra comum.( BLIKSTEIN, 2002, p.20)

Logo, quando não conseguimos tornar comum o nosso pensamento ao outro, corremos o risco de que ocorra um mal-entendido no significado de algumas palavras, como se pode compreender também em :

[...] os mal-entendidos que podem produzir-se entre os utilizadores de um código erudito (médicos, juízes, etc.) e os simples profanos, tanto ao nível sintático como no nível lexicológico, sendo os mais significativos os que surgem quando as palavras da linguagem vulgar, desviadas do seu sentido comum pelo uso erudito, funcionam para o profano como "falsos amigos".(BOURDIEU 1989, p. 227)

Um exemplo disso seria o significado da palavra "resolução", que normalmente significa, "maneira através da qual se resolve uma questão", mas no contexto jurídico seria, a "dissolução de um contrato". Considerando que as questões jurídicas estão relacionadas a assuntos de ordem social e que Nader (2012) designa que as normas jurídicas são estabelecidas de acordo com a natureza do homem e em função dos seus interesses, nada seria mais compassivo do que o a linguagem do processo jurídico ser acessível à sociedade.

Por isso, entendemos que uma comunicação de qualidade e eficiente entre os operadores do direito e o cidadão leigo, precisaria ser dentro de uma linguagem mais acessível. O distanciamento causado pelo uso de termos muito técnicos faz com que o 
direito perca sua referência, que seria a de "função social", que é o princípio estruturante de todo o ordenamento jurídico.

\section{A LINGUÍSTICA E O DIREITO}

A contribuição de Bagno, linguista, autor da o Preconceito Linguístico - O que é, como se faz -, é a discussão sobre as implicações sociais da língua. Bagno (2007) preconiza algumas maneiras para amenizar o preconceito linguístico. Primeiramente, segundo o autor é preciso mudar de atitude e valorizar o saber de cada indivíduo, discordando das pessoas que menosprezam as diversas maneiras de falar.

Parece haver cada vez mais, nos dias de hoje, uma forte tendência a lutar contra as mais variadas formas de preconceito, a mostrar que eles não têm nenhum fundamento racional, nenhuma justificativa, e que são apenas o resultado da ignorância, da intolerância ou da manipulação ideológica. Infelizmente, porém, essa tendência não tem atingido um tipo de preconceito muito comum na sociedade brasileira: o preconceito linguístico. Muito pelo contrário, o que vemos é esse preconceito ser alimentado diariamente em programas de televisão e de rádio, em colunas de jornal e revista, em livros e manuais que pretendem ensinar o que é "certo" e o que é "errado", sem falar, é claro, nos instrumentos tradicionais de ensino da língua: a gramática normativa e os livros didáticos. ( BAGNO, 2007, p.12)

Essa discussão contribuiu para uma ponderação também na área de atuação do Direito. Não propriamente analisando o preconceito da linguagem, mas os desdobramentos deste preconceito na comunicação jurídica.

O Direito tem sua origem nos acontecimentos da sociedade onde a normatização se reflete nos costumes, tradições, valores, sentimento e cultura dos povos. Então se a prática jurídica é tão ampla, ela não pode excluir, mas deve sim unir, ser justa com o cidadão. E ser justa é também adequar seus termos às pessoas que não possuem o conhecimento técnico da área jurídica. Uma pessoa mais humilde, de classe social mais baixa não se sente acolhida e representada por um Judiciário que não demostra fazer esforço para que ela tome conhecimento de assuntos relativos ao seu interesse. 
...compara o "juridiquês" ao latim em missa, acobertando um mistério que amplia a distância entre a fé e o religioso; do mesmo modo, entre o cidadão e a lei. Ou seja, o uso da linguagem rebuscada, incompreensível para a maioria seria também uma maneira de demonstração de poder e de manutenção do monopólio do conhecimento. (ALVARENGA, 2005 in ANDRADE).

E em virtude de sermos um país com uma grande diferença na distribuição de renda, cria-se também uma grande diferença de status social. Para Bagno (2007, p. 42), “o preconceito linguístico é decorrência de um preconceito social”, e constatamos isso ao percebermos que a maior parte das pessoas conhecedoras da norma culta da língua, se incomoda ao ouvir algo que não condiz com as regras gramaticais.

Entretanto, é preciso reconhecer que estamos diante de uma sociedade muito desigual, em que existe uma parcela considerável de indivíduos desprestigiados e marginalizados, que não possuem acesso à educação. Cabe destacar que a discussão tecida neste trabalho não busca de modo algum desqualificar o uso da norma culta, mas sim questionar sua aplicabilidade e os excessos cometidos pelo juridiquês ao destinar-se a pessoas que não possuem instrução suficiente para decodificar as mensagens ali transmitidas. Questiona-se aqui, o processo de comunicação.

Diante dessa situação, percebe-se a necessidade de que o linguajar jurídico seja de certa forma simplificada, pois quem não conhece sequer a norma culta, dificilmente entenderá os jargões utilizados no âmbito jurídico. As autoras entendem que os termos técnicos são necessários, mas que seu uso deve ser feito entre pessoas do mesmo grupo, pois fará mais sentindo mediante a compreensão por parte de todos. Afinal, Nascimento (2015) esclarece que existem estudos que comprovam que 'falar difícil' não demonstram inteligência, mas pelo contrário, as pessoas são vistas como inteligentes quando conseguem tornar inteligível algo que é complexo.

Em vista dessas e de muitas outras razões, a utilização do "juridiquês” vem sendo rejeitada gradativamente e lentamente por alguns juízes, que sentenciam de forma mais clara e acessível. Um exemplo disso foi a sentença dada no dia 23 de abril de 2015, pelo então juiz João Batista de Matos Danda, do Tribunal Regional da $4^{\text {a }}$ Região quando o mesmo fez uso de uma linguagem coloquial para redigir a sentença, tornando-a um 
texto de fácil compreensão, seguindo uma tendência em fazer sentenças mais claras, mas sem perder a precisão técnica, mostrando a viabilidade da utilização de um linguajar mais simples facilitando a compreensão e a inclusão assim de todos no âmbito jurídico.

Seguindo também essa tendência, em 2005 a Associação de Magistrados Brasileiros (AMB) lançou uma cartilha e uma campanha com esse propósito. A página de internet do Senado Federal já tem uma aba de explicação da ementa.

\section{Considerações Finais}

Nota-se que a precisão da linguagem e o uso correto do vernáculo são importantes à eficácia da comunicação.

Atribui-se ao domínio da linguagem a própria evolução humana, no entanto, foi exposta, inicialmente, neste trabalho, a intenção de considerar-se de que forma um linguajar mais simples e condizente com a realidade sociocomunicativa do nosso país, pode colaborar com o acesso à justiça e fazer com que o cidadão se sinta inserido na sociedade e na prerrogativa de seus direitos.

As variações linguísticas trazem características próprias que enriquecem a pluralidade cultural do nosso país. É através delas que podemos nos expressar de diversas formas, aplicando-as em diversos contextos sociais.

Após análise dos autores que defendem esse posicionamento de uma linguagem mais simples, clara e objetiva, é possível perceber que lentamente está havendo uma mudança no sentido do uso de uma linguagem mais acessível nas peças judiciárias, afinal, a nossa sociedade tem por princípio fundamental a igualdade. Assim sendo, o Direito deve ser o primeiro a ser um instrumento de democratização, deixando de monopolizar seu discurso e sendo exemplo para que haja mudança também em outros setores, onde esteja havendo também uma exclusão social em função da linguagem.

Há os que defendem o uso de uma linguagem técnica rebuscada do Direito, estes afirmam que, assim como qualquer outra ciência, se faz necessário o uso da sua própria linguagem técnica, mas partindo-se do princípio que dentro da área do Direito, a principal ferramenta é a comunicação, então não podemos privar as pessoas da mesma, se não existir uma linguagem clara entre os operadores do direito e a sociedade não haverá efetivamente a comunicação. 
Enfim, no Direito, a linguagem revela o cuidado do operador do Direito, o uso de uma expressão inadequada, mal compreendida, pode ser o diferencial entre o sucesso e o fracasso de uma causa, no entanto a aplicação da linguagem técnica jurídica sem o cuidado devido por parte do Poder Judiciário, bem como daqueles profissionais da área, pode não tornar comum e claro o que se pretende comunicar, causando danos à dignidade da pessoa humana.

\section{Referências}

ANDRADE, Valdeciliana da Silva Ramos. $O$ juridiquês e a linguagem: o certo e o errado no discurso. Direito legal, [2015]. Disponível em:

https://www.direitolegal.org/seus-direitos/o-juridiques-e-linguagem-juridica/

. Acesso em: 24 out. 2018.

ARAÚJO, Eneida Maria Erre; DIAS, Ilzenir Silva. Domínio da norma culta da língua portuguesa como determinante de inclusão/exclusão no mundo do trabalho. Revista de Políticas Públicas. São Luís, Universidade Federal do Maranhão, v.18, n 1, janeirojunho de 2014, p. 255-268.

BAGNO, Marcos. Preconceito Linguístico: o que é como se faz. 49a ed. São Paulo: Loyola, 2007.

BLIKSTEIN, Izidoro. Técnicas de comunicação e escrita. 20ª ed. São Paulo: Ática, 2002.

BOURDIEU, Pierre. O poder simbólico. Lisboa: Difel, 1989.

IBGE, Diretoria de Pesquisas, Coordenação de Trabalho e Rendimento, Pesquisa Nacional por Amostra de Domicílios. 2007/2015. Disponível em < https://brasilemsintese.ibge.gov.br/educacao/taxa-de-analfabetismo-das-pessoas-de-15anos-ou-mais.html> Acesso em 08 jun. 2019.

MIGUEIS, Ana Gláucia Lobato Campos. A função social do Direito. Jusbrasil, 2016. Disponível em: https://anaglc.jusbrasil.com.br/artigos/450535880/a-funcao-social-dodireito. Acesso em: 24 out. 2018. 
NADER, Paulo. Introdução ao estudo do direito. 34. ed. Rio de Janeiro: Forense, 2012.

NASCIMENTO, Carlos Henrique Rodrigues Nascimento. Repercussão! Magistrado faz sentença em linguagem coloquial para combater 'Juridiquês'. Jusbrasil, 2015.

Disponível em: https://chrn.jusbrasil.com.br/noticias/408498443/repercussaomagistrado-faz-sentenca-em-linguagem-coloquial-para-combater-juridiques. Acesso em: 02 nov. 2018.

OLIVEIRA, Mayara Costa. Linguagem jurídica: quando o formalismo interfere na comunicação. Brasília: 04 ago.2015. Disponível em:

<http://www.conteudojuridico.com.br/?artigos\&ver=2.54147\&seo=1>. Acesso em: 15 out. 2018. 